\title{
Effect of ketofol versus propofol as an induction agent on ease of laryngeal mask airway insertion conditions and hemodynamic stability in pediatrics: an observational prospective cohort study
}

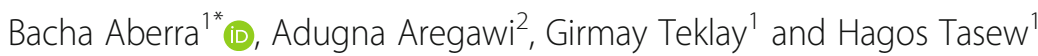

\begin{abstract}
Background: Laryngeal mask airway is a supraglottic airway device which has led to a fundamental change in the management of modern general anesthesia. In the present study; we evaluated the laryngeal mask airway insertion conditions and hemodynamic changes comparing ketamine-propofol mixture (ketofol) with propofol. The study was to compare the ketamine-propofol mixture (ketofol) with propofolon the ease of laryngeal mask airway insertion conditions and hemodynamic effects for induction of general anesthesia.

Methods: One hundred twenty pediatric patients were recruited and assigned to two groups (60 each). Group $\mathrm{KP}=$ ketofol, group $\mathrm{P}=$ propofol. Insertion conditions were compared using a Chi-square test while hemodynamic variables were compared using the independentt-test. Statistical significance was stated at $p$-value $<0.05$.

Results: Laryngeal mask airway insertion summed score was nearly similar between the two groups. Mean blood pressure and heart rate were maintained higher in ketofol group while a significant drop was observed in the propofol group. The time from the Laryngeal mask airway placement to the return of spontaneous ventilation was significantly longer in propofol group (240 s [range $=60-360 \mathrm{~s}])$ compared with ketofol group (180 s [range $=30-320 \mathrm{~s}])(p=0.005)$.

Conclusions: Laryngeal mask airway insertion condition summed score was comparable in both ketofol and propofol group. Ketofol provided equivalent laryngeal mask airway insertion conditions while maximizing hemodynamics and minimizing apnea time. Ketofol can be used as an alternative to propofol for laryngeal mask airway insertion in pediatrics.
\end{abstract}

Keywords: Hemodynamics, Ketofol, Laryngeal mask airway insertion, Propofol

\section{Background}

The most important duty of an anesthetist is the management of airway to deliver sufficient ventilation to the patient by securing airway while general anesthesia is administered. As such, no anesthesia is safe unless meticulous efforts are devoted to maintain an intact and functional airway [1,2]. Effective insertion of the LMA entails optimum anesthetic depth to

\footnotetext{
* Correspondence: bcabera11@gmail.com

${ }^{1}$ Aksum University, PO box 298, Aksum City, Tigray, Ethiopia

Full list of author information is available at the end of the article
}

elude undesirable airway reflexes such as swallowing, gagging, coughing or involuntary movements to severe problems such as laryngospasm $[3,4]$.

Adequate anesthetic induction situations are paramount delivered by propofol compared to other intravenous induction agents [4]. Nevertheless, when propofol is used as a single induction agent without premedication, doses greater than $3 \mathrm{mg} / \mathrm{kg}$ is necessary for smooth LMA insertion [5, 6]. On the other hand, increased propofol doses are not required as undesirable cardio-respiratory depression is dose-dependent [7, 8]. Several combinations of pharmacological agents have

(c) The Author(s). 2019 Open Access This article is distributed under the terms of the Creative Commons Attribution 4.0 International License (http://creativecommons.org/licenses/by/4.0/), which permits unrestricted use, distribution, and reproduction in any medium, provided you give appropriate credit to the original author(s) and the source, provide a link to the Creative Commons license, and indicate if changes were made. The Creative Commons Public Domain Dedication waiver (http://creativecommons.org/publicdomain/zero/1.0/) applies to the data made available in this article, unless otherwise stated. 
been introduced to decrease the hemodynamic instability in anesthesia $[9,10]$. Ketamine is well known for its airway reflexes maintaining activity and sympathetic cardiorespiratory stimulant so as to causes little or no cardiorespiratory depression and unlike propofol has pain relieving properties $[11,12]$.

Hemodynamic stability can be maintained using a combination of ketamine and propofol (ketofol), as there is additive effect of Gamma-aminobutyric acid (GABA) agonism by propofol and N-Methyl-D-Aspartate (NMDA) antagonism by ketamine leading to lesser doses of propofol required along with ketamine [13]. The effectiveness of the two agents, propofol and ketamine, may provide the best induction agent with favorable hemodynamics and decreased side effects attributed to either drug as clinical effects of propofol and ketamine seem to be complementary [14].

Therefore the finding of this research will help anesthesia professionals to provide safe and effective alternative induction agent for better LMA insertion conditions and improved hemodynamic stability. It also helps health administrators to work on quality improvement, enhancing good patient outcome, supplying cost-effective anesthetic drugs with the better patient outcome and enhancing income generation and cost reduction.

\section{Methods}

\section{Study objective}

The aim of this study was to compare the effect of the ketamine-propofol mixture (ketofol) and propofol on the insertion conditions of laryngeal mask airway and hemodynamic stability in pediatrics.

\section{Study design}

An observational prospective cohort study was employed from Jan 25-March, 25, 2017 after ethical approval (No-11/2009, Dec 1, 2016) was obtained from the Addis Ababa University Ethical committee.

\section{Study setting}

This study was conducted at Menelik-II Hospital. Menelik II hospital is one of the largest hospitals in the country. Menelik-II Hospital is now the main health provider center that offers high-quality comprehensive health services to the patient from all over the region of Ethiopia and there are two main operation departments, from which ophthalmic operation room has six operation tables. One of these is pediatric operation room table, which on average, 1920 pediatric patients operated under general anesthesia per year. The study was conducted from January 25-March 25, 2017.

\section{Study participants}

Patients of ASA class I and II, age ranging from 2 to 15 years and undergoing elective surgical procedures under GA using LMA were included in the study. Patients with hyper-reactive airway disease anticipated difficult airway, on regular sedatives and on $\beta$-blockers were excluded from the study.

\section{Study variables}

In this study, the dependent variables were ease of LMA insertion and hemodynamic changes. The independent variables were socio-demographic and operative data (Age, Sex Weight, ASA, and Mallampati class) and another exposure variable (a type of anesthesia drugs used (ketofol vs. propofol)) Table 1.

\section{Sample size and sampling techniques determination}

StatCalc EPI info 7.1.1 (Fleiss) was used based on ease of LMA insertion conditions among two groups to calculate the sample size for each group. The following assumptions were considered to estimate the sample size required for the study. A 95\% confidence level and 80\% power, equal sample size for two groups, a proportion of

Table 1 operational definitions

\begin{tabular}{|c|c|c|}
\hline \multicolumn{3}{|c|}{ Operational Definitions } \\
\hline Apnea & \multicolumn{2}{|c|}{$\begin{array}{l}\text { The absence of spontaneous respiration for }<20 \mathrm{~s} \\
\text { after induction }\end{array}$} \\
\hline \multirow[t]{2}{*}{ Ease of insertion } & Easy & $\begin{array}{l}\text { No adverse response, i.e., gagging or } \\
\text { coughing, movement or laryngospasm }\end{array}$ \\
\hline & Difficult & $\begin{array}{l}\text { Moderate to severe adverse responses } \\
\text { requiring additional boluses of drugs } \\
\text { or more than two attempts are } \\
\text { required for LMA insertion }\end{array}$ \\
\hline \multirow[t]{2}{*}{ Laryngospasm } & Complete & $\begin{array}{l}\text { when there are laryngeal spasm and } \\
\text { no air entry on ventilation }\end{array}$ \\
\hline & Incomplete & $\begin{array}{l}\text { when there is laryngeal spasm but } \\
\text { there is air entry }\end{array}$ \\
\hline \multirow[t]{2}{*}{ Coughing } & Slight & $\begin{array}{l}\text { coughing which can occur } \\
\text { immediately after LMA and subside by } \\
\text { itself }\end{array}$ \\
\hline & Gross & $\begin{array}{l}\text { coughing which needs deepening of } \\
\text { anesthesia to be relieved }\end{array}$ \\
\hline \multirow[t]{2}{*}{ Gagging [23] } & Slight & $\begin{array}{l}\text { Gagging which stays for short seconds } \\
\text { can relieve on its own }\end{array}$ \\
\hline & Gross & $\begin{array}{l}\text { Gagging which needs deepening of } \\
\text { anesthesia to be relieved }\end{array}$ \\
\hline \multirow[t]{2}{*}{ Patient movement } & Slight & $\begin{array}{l}\text { Movement from small muscles which } \\
\text { can allow insertion of LMA without an } \\
\text { additional dose of the drugs }\end{array}$ \\
\hline & Gross & $\begin{array}{l}\text { The movement which cannot be } \\
\text { relieved without an additional dose of } \\
\text { the drugs }\end{array}$ \\
\hline
\end{tabular}

Insertion condition Summing the insertion score for each patient then summed score totaling the score for all patients in the groups and taking the mean 
subjects with poor insertion conditions were 41.66 and $18.33 \%$ in propofol (unexposed) and ketofol (exposed) group respectively in a recent study $[15,16]$. A total of 60 ASA I and II pediatric patients age 2-15 were assigned to each group.

\section{Sampling technique}

From situational analysis mean of midyear population was used to get a total number of ophthalmic pediatric patients who underwent operation under general anesthesia using LMA in 2 months duration. The midyear population from the situational analysis was 960 . So, the size of the population in 2 months was $960 \mathrm{di}-$ vided by three gives us 320 . The study participants were selected using a systematic sampling technique every two participants from daily operation schedule list until the required sample size was obtained. The first study participants were selected by lottery method. We spent two extra weeks to reach the number of propofol group is equal to ketofol group to get an equal sample size in both groups.

\section{Intraoperative procedure}

After preoperative preparation, patients were shifted to the operation room, standard monitoring applied as routine. Baseline vitals were recorded and I.V. fluids were administered. Patients were preoxygenated with $6 \mathrm{~L} / \mathrm{min}$ of Oxygen via a face mask, for 3 min and given injection atropine $0.02 \mathrm{mg} / \mathrm{kg} \mathrm{I.V}$. and fentanyl $1 \mu \mathrm{g} / \mathrm{kg} \mathrm{I}$. V prior to induction as the standard of care.

LMA insertion was performed $60 \mathrm{~s}$ after induction of anesthesia [1]. Following insertion, the position of LMA was assessed by observing movement of chest and reservoir bag through use of both spontaneous and assisted ventilation. After successful insertion of LMA, patients were allowed to breathe spontaneously. Assisted manual ventilation provided when the apnoea period is longer than $20 \mathrm{~s}$ from the time of LMA insertion to ensure that SpO2 remained above 95\%. Manual ventilation was stopped when sufficient spontaneous respiration returned. Thereafter, anesthesia was maintained with isoflurane $2 \%$ and oxygen $100 \%$ with a flow rate of $3 \mathrm{~L} /$ min.

The patients were either induced with ketofol $(0.5 \mathrm{mg} /$ $\mathrm{kg}$ of ketamine plus $3.0 \mathrm{mg} / \mathrm{kg}$ of propofol) or $3.5 \mathrm{mg} / \mathrm{kg}$ or propofol alone. If the patients respond to stimulus after induction, further increments of propofol 0.5-1 $\mathrm{mg} / \mathrm{kg}$ were given until loss of consciousness and loss of eyelash reflex in either technique. All patients who were exposed to either ketofol or propofol were compared to see different outcomes of both agents as an induction agent on ease of laryngeal mask airway insertion and hemodynamic stability. Insertion condition was graded by the same anesthetist who performs the procedure as [9]. a) Mouth opening: 1 - Full, 2 - Partial, 3 - Nil

b) Coughing: 1 - Nil, 2 - slight, 3 - gross

c) Swallowing: 1 - Nil, 2 - slight, 3 - gross

d) Movement: 1 - Nil, 2 - slight, 3 - gross

e) Laryngospasm: 1 - Nil, 2 - Mild, 3- Severe

f) Ease of LMA insertion: 1-Easy, 2-Difficult, 3Impossible

Mean blood pressure and heart rate were recorded one minute before induction (baseline), immediately after induction, immediately after LMA insertion, then at every minute for up to $3 \mathrm{~min}$. The duration of apnoea was recorded via a digital timer as the time from the end of induction of anesthesia until the return of adequate spontaneous ventilation. Afterward, all patients who were scheduled for ophthalmic surgical operation under general anesthesia with LMA were enrolled in the study and assigned to either ketofol or propofol group randomly. Our study used those patients induced with propofol as a cohort group, where the same checklist was used to observe the case.

\section{Data collection technique and instrument}

Data were collected using a pretested observational checklist. Data collectors were three bachelor degree holder anesthetist and they supervised by one master degree holder anesthetist. All anesthetists participating in the study including anesthetists who inserts the LMAs and administers the medications had at least 2 years of experience in conducting anesthesia.

\section{Data quality assurance}

Before recruiting patients into the study, training and orientation about the objective and process of data collection were provided by the principal investigator. To ensure the quality of data, a pre-test of the checklist was performed in Cure International Hospital before the actual data collection time. The completed checklist was submitted and reviewed on daily basis. Close supervision and daily information exchange were used as a means to correct problems during the course of data collection.

Consent for the survey was obtained from Addis Ababa University College of health sciences and confidentiality assured to improve the quality of data. Variables were checked by the expert before the actual data collection period for the purpose of consistency.

\section{Statistical methods}

All data were analyzed by SPSS statistical package program (Version 20). Within the groups, the normality of variables was measured using the Shapiro-Wilk test. Differences of numerical data between groups were evaluated using student's t-test and Mann-Whitney 
U-test when appropriate. Categorical data were analyzed with the Chi-Square test. A $p$ value of $<0.05$ with the power of $80 \%$ was regarded as statistically significant.

\section{Results}

\section{Socio-demographic features and operative conditions}

A total of 120 patients were enrolled and none were excluded from the study as there was no incidence of failed LMA insertion. There were no statistically significant differences in age, sex, weight, and ASA or mallampati class between groups [Table 2].

\section{Comparison of ease of insertions conditions}

In $12(20 \%)$ of the propofol group patients, additional $0.5-1 \mathrm{mg} / \mathrm{kg}$ ) propofol was required as compared to nine $(15 \%)$ of those in the ketofol group. However, no significant difference was noted between the two groups ( $p=$ 0.631). The time from the LMA placement to the return of spontaneous ventilation was significantly longer in propofol group (240 s [range $=60-390 \mathrm{~s}$ ]) compared with a ketofol group (180 s [range $=30-380 \mathrm{~s}$ ] $)(p=0.005)$, expressed in median and range respectively. The LMA was inserted successfully and positioned correctly on the first attempt in $95 \%$ of patients receiving ketofol compared with $96.67 \%$ in patients receiving propofol [Table 3].

LMA insertion summed score was nearly similar between the two group, which were statistically insignificant $(p=0.511)$. No patient developed laryngospasm in the ketofol group while 2 patients (3.33\%) developed partial laryngospasm in propofol group but not statistically significant $(p=0.154)$ [Table 4].

Table 2 Socio-demographic features of the patients

\begin{tabular}{|c|c|c|c|}
\hline $\begin{array}{l}\text { Patient } \\
\text { characteristics }\end{array}$ & $\begin{array}{l}\text { Group KP } \\
(n=60)\end{array}$ & $\begin{array}{l}\text { Group P } \\
(n=60)\end{array}$ & $P$-value \\
\hline Age in years (median, IQR ${ }^{a}$ ) & $5.5(3-9)$ & $7(4-11)$ & 0.18 \\
\hline Gender (n, \%) & & & 1.00 \\
\hline Male & $34(56.7)$ & $35(58.3)$ & \\
\hline Female & $26(43.3)$ & $25(41.7)$ & \\
\hline Weight (median, IQR ${ }^{*}$ ) (in Kgs ${ }^{\mathrm{b}}$ ) & $19.5(14-25)$ & $26(15-30)$ & 0.14 \\
\hline ASA $(n, \%)$ & & & 0.611 \\
\hline I & $57(95.0)$ & $59(98.3)$ & \\
\hline$\|$ & $3(5.0)$ & $1(1.7)$ & \\
\hline Mallampati class $(n, \%)$ & & & 0.756 \\
\hline Can't be assessed ${ }^{c}$ & $18(30)$ & $16(26.7)$ & \\
\hline । & $40(66.7)$ & $43(71.7)$ & \\
\hline$\|$ & $2(3.3)$ & $1(1.7)$ & \\
\hline
\end{tabular}

Table 3 Requirement of Additional propofol, duration of apnea and attempts of LMA

\begin{tabular}{llll}
\hline & Group KP & Group P & $p$-value \\
\hline $\begin{array}{l}\text { The requiredtop-up dose } \\
\text { of propofol ( } n \text {, \%) }\end{array}$ & $9(15)$ & $12(20)$ & 0.631 \\
$\begin{array}{l}\text { Duration of apnea (seconds) } \\
\begin{array}{l}\text { Attempts of LMA } \\
\text { insertion(1/2/3) }\end{array}\end{array}$ & $180^{\mathrm{a}}\left(30-380^{\mathrm{b}}\right)$ & $240^{\mathrm{a}}\left(60-390^{\mathrm{b}}\right)$ & 0.005 \\
\hline
\end{tabular}

${ }^{\mathrm{a}}=$ Median, ${ }^{\mathrm{b}}=$ range

\section{Comparison of hemodynamic characteristics}

Patients in both groups were comparable with respect to preoperative baseline hemodynamic conditions. The mean arterial pressure difference between the group is not significantly different before induction ( $p$-value $=0.263$; is insignificant). With the induction of anesthesia, a significant drop in mean arterial blood pressure was observed in propofol group from baseline while in the ketofol group, there was a rise in mean arterial pressure at all measurement times $(P<0.001)$ [Fig. 1]. Maximum mean blood pressure was $81.5 \pm 11.02 \mathrm{mmHg}$ with a ketofol group seen immediately after induction [Table 5].

Preoperatively there was no statistically significant difference ( $p$-value $>0.05)$ between the heart rate of both groups. $P$ values at all levels after induction were $<0.05$ and statistically significant. With the induction of anesthesia, a significant rise in heart rate was observed in the ketofol group from baseline while in propofol group, there was a drop in heart rate at all measurement times $(P<0.05)$ [Fig. 2]. The increment in heart rate was seen immediately after induction compared with baseline. Maximum heart rate was $118.55 \pm 24.86$ beat $/ \mathrm{min}$ with a ketofol group seen immediately after LMA insertion. Minimum heart rate $(99.62 \pm 25.071)$ was seen in propofol group $3 \mathrm{~min}$ after LMA insertion [Table 6].

Table 4 Comparison of insertion conditions of LMA between the ketofol and propofol groups

\begin{tabular}{llll}
\hline Assessment grades & Group KP & Group P & $p$ value \\
\hline $\begin{array}{l}\text { Mouth opening } \\
\text { (Full / Partial/None) }\end{array}$ & $54 / 6 / 0$ & $53 / 7 / 0$ & 0.769 \\
$\begin{array}{l}\text { Coughing or gagging } \\
\text { (Nil / Slight/Gross) }\end{array}$ & $54 / 6 / 0$ & $52 / 7 / 1$ & 0.573 \\
$\begin{array}{l}\text { Swallowing } \\
\text { (Nil / Slight/Gross) }\end{array}$ & $55 / 5 / 0$ & $54 / 5 / 1$ & 0.604 \\
$\begin{array}{l}\text { Laryngospasm } \\
\text { (Nil / Partial/Complete) }\end{array}$ & $60 / 0 / 0$ & $58 / 2 / 0$ & 0.496 \\
$\begin{array}{l}\text { Ease of LMA insertion } \\
\text { (easy/difficult/impossible) }\end{array}$ & $59 / 1 / 0$ & $58 / 2 / 0$ & 0.956 \\
$\begin{array}{l}\text { Head or limbs movement } \\
\text { (Nil / Slight/Gross) }\end{array}$ & $57 / 3 / 0$ & $58 / 2 / 0$ & 0.648 \\
$\begin{array}{l}\text { Insertion condition } \\
\text { summed score }\end{array}$ & 6.35 (6-10) & 6.48 (6-13) & 0.607 \\
\hline
\end{tabular}




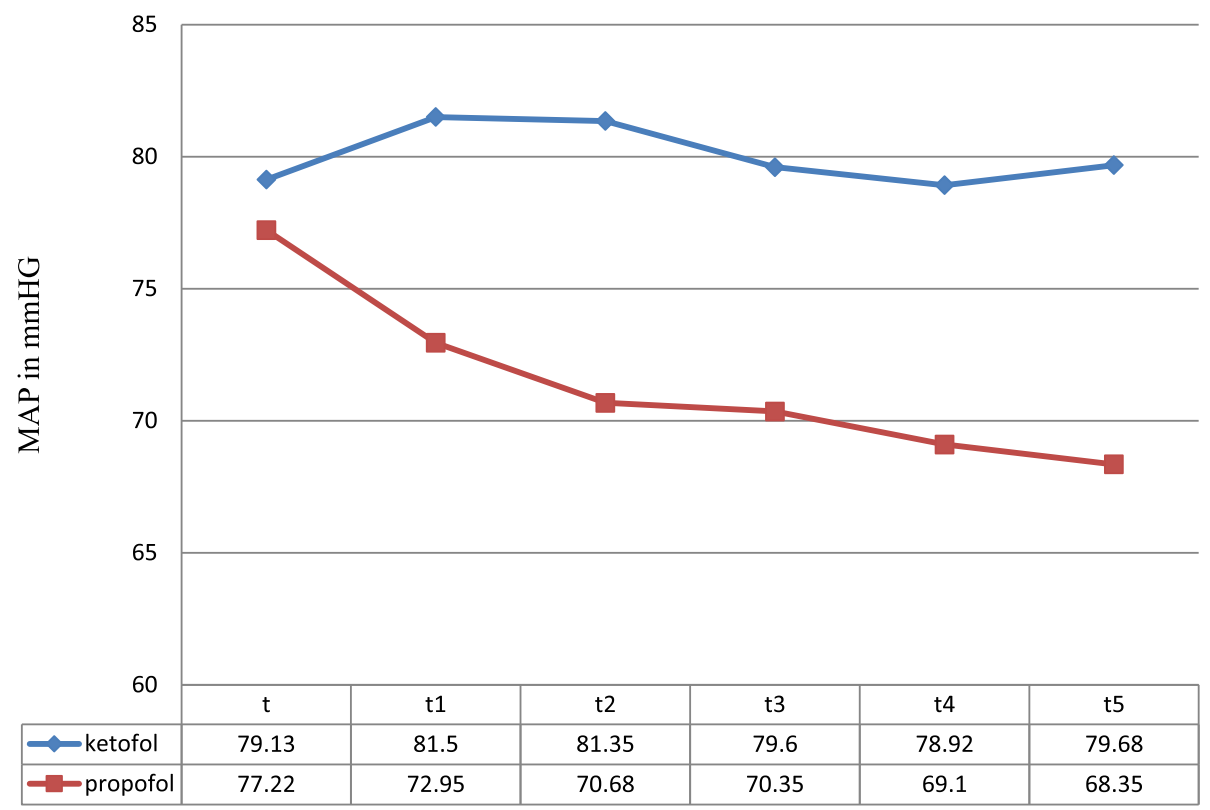

Fig. 1 Changes in mean arterial pressure between ketofol and propofol group. NB: t, baseline, t1, immediately following induction of anesthesia, t2, immediately after LMA placement, $\mathrm{t} 3, \mathrm{t} 4$, and $\mathrm{t} 5,1,2$ and 3 min after LMA placement

\section{Discussion}

In our study, LMA insertion summed score for ketofol and propofol group were nearly similar. This result coincides with the studies done by Goh et al. in their study of randomized double-blind comparison of ketamine-propofol, fentanyl-propofol and propofol-saline on hemodynamics and laryngeal mask airway insertion conditions [17].

In our study, in ketofol group, we observed a decrease in the requirement of an additional dosage of propofol for induction, although it was not statistically significant $(p>0.05)$. Consistent with our results, many researchers observed that there was a significant decrease in additional requirement of propofol for induction, loss of consciousness and LMA insertion in ketofol group than propofol group. This less requirement of additional propofol dose is due to the combined effect of ketamine and propofol at both hypnotic and anesthetic endpoints $[2,12,18]$. However, the reason for the insignificant result in our study might have been due to the use of 3.5 $\mathrm{mg} / \mathrm{kg}$ (high dose) of propofol for induction unlike Yousef et al. [12]. They administered initial $2 \mathrm{mg} / \mathrm{kg}$ propofol and incremental doses of propofol until the target level of the Bispectral index of 40 was obtained.

This study also spectacles that, apnea time was significantly longer in propofol group $($ median $=240 \mathrm{~s}$ [range $=$ $60-390 \mathrm{~s}]$ ) compared with ketofol group (median $=180 \mathrm{~s}$ [range $=30-380 \mathrm{~s}]) \quad(p=0.005)$. Consistent with our study [19] in their study of comparison of propofol and ketofol on laryngeal tube-suction II circumstances and hemodynamics showed that apnea duration was longer in group $\mathrm{P}($ median $=385 \mathrm{~s} \quad[$ range $=195-840 \mathrm{~s}$ ] $)$ compared with group KP (median $=325.5 \mathrm{~s}$ [range $=$ $60-840 \mathrm{~s}]$ ) but was not statistically significant [19]. In their study, the overall apnea time was higher than ours. This difference might have been due to the use of remifentanil $(1 \mu \mathrm{g} / \mathrm{kg}) 60 \mathrm{~s}$ after pre-oxygenation because remifentanil is known to have prolonged apnea time than fentanyl [13].

Table 5 Comparing the Mean of data on mean arterial blood pressure between ketofol and propofol groups

\begin{tabular}{llll}
\hline & Mean arterial pressure (in mmHg) & & $P$ value \\
\cline { 2 - 3 } & Group KP (Mean \pm SD) & Group P (Mean \pm SD) & 0.263 \\
\hline Baseline MAP & $79.13 \pm 8.96$ & $77.22 \pm 9.69$ & $<0.001$ \\
Immediately after induction & $81.50 \pm 11.02$ & $72.95 \pm 12.349$ & $<0.001$ \\
Immediately after LMA insertion & $81.35 \pm 11.339$ & $70.68 \pm 11.620$ & $<0.001$ \\
One minute after LMA insertion & $79.60 \pm 11.036$ & $70.35 \pm 10.844$ & $<0.001$ \\
Two minute after LMA insertion & $78.92 \pm 11.794$ & $69.10 \pm 10.188$ & $<0.001$ \\
Three minute after LMA insertion & $79.68 \pm 11.978$ & $68.35 \pm 9.295$ & \\
\hline
\end{tabular}




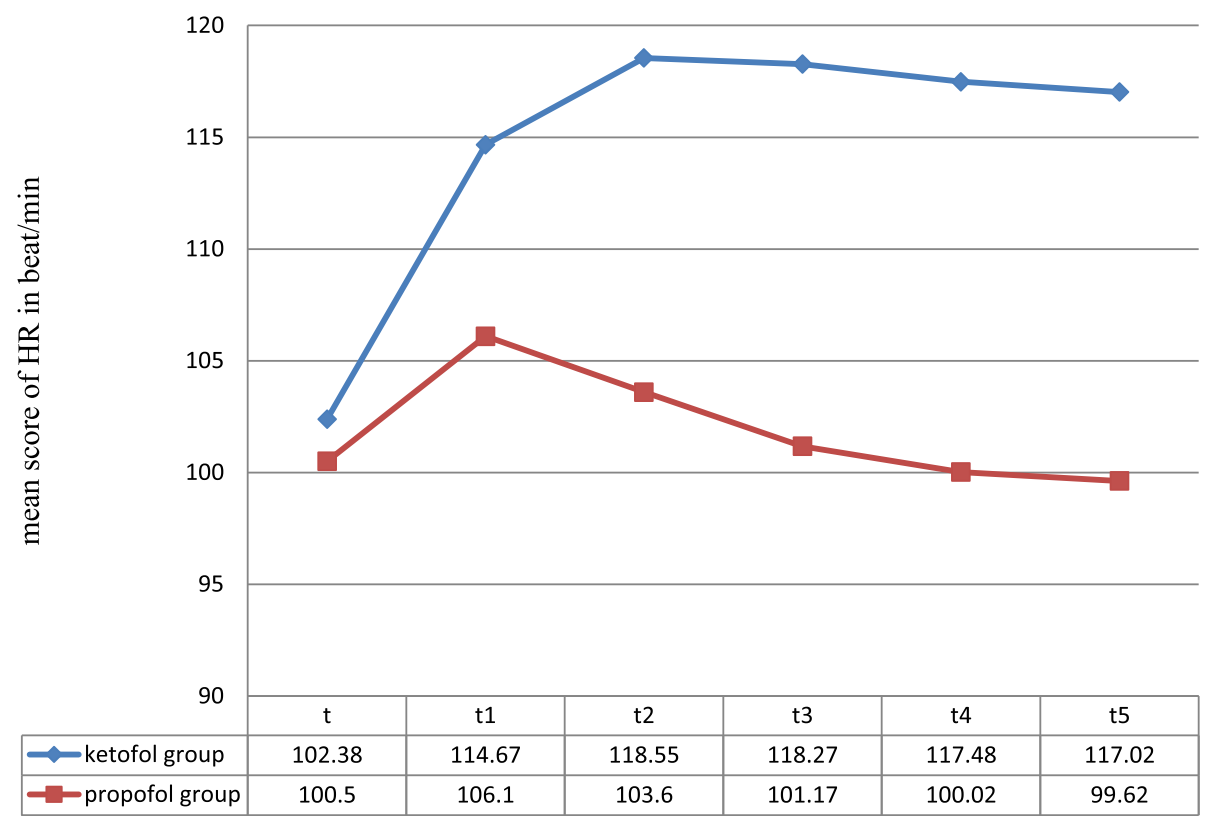

Fig. 2 Changes in heart rate between ketofol and propofol group. NB: t, baseline, t1, immediately following induction of anesthesia, t2, immediately after LMA placement, $\mathrm{t} 3, \mathrm{t} 4$, and $\mathrm{t} 5,1,2$ and 3 min after LMA placement

A comparative study done in Malaysia to compare the effects of ketamine and midazolam as co-induction agents with propofol for prosea ${ }^{\mathrm{m}}$ laryngeal mask airway insertion showed that the ketamine-propofol combination had a shorter duration of apnoea, better mouth opening, and hemodynamic profile as compared to the combination midazolam-propofol [1].

Another Randomized double-blind comparative study of ketamine-propofol and fentanyl-propofol for LMA insertion in children showed that the conditions of LMA insertion were superior in the combination of ketamine $(0.5 \mathrm{mg} / \mathrm{kg}$ and propofol than propofol and fentanyl [20].

Hemodynamic parameters can increase $20 \%$ after LMA insertion, with an additional 30\% after orotracheal intubation [1]. In our study, we observed that ketofol preserved mean arterial pressure at all measurement times while a significant drop in mean arterial blood pressure was seen in the propofol group. Similarly, several studies concluded that ketofol is superior to propofol and propofol-thiopentone mixture because of its better hemodynamic stability $[11,17,21,22]$. With the induction of anesthesia, a significant rise in heart rate was observed in ketofol group from baseline while in propofol group, there was a drop in heart rate at all measurement times $(P<0.05)$. The cardiovascular stimulant effect of ketofol is desirable especially in pediatric anesthesia while the unduly depressant effect of propofol is unwanted $[11,12]$.

\section{Limitations}

This study was unable to measure anesthetic depth. Therefore the LMA insertion conditions may have been adversely affected and hemodynamic parameters change might be observed. Use of fentanyl in both groups before induction may have affected the hemodynamic effects of the agents.

Table 6 Comparing the Mean of data on heart rate between ketofol and propofol group

\begin{tabular}{llll}
\hline & Heart rate (beat per minute) & & \\
\cline { 2 - 3 } & Group KP (Mean \pm SD) & Group P (mean \pm SD) & \\
\hline Baseline heart rate & $102.38 \pm 16.368$ & $100.50 \pm 17.070$ & 0.539 \\
Immediately after induction & $114.67 \pm 21.972$ & $106.10 \pm 21.802$ & 0.034 \\
Immediately after LMA insertion & $118.55 \pm 24.863$ & $103.60 \pm 23.449$ & $<0.001$ \\
One minute after LMA insertion & $118.27 \pm 22.823$ & $101.17 \pm 24.668$ & $<0.001$ \\
Two minute after LMA insertion & $117.48 \pm 20.994$ & $100.02 \pm 25.780$ & $<0.001$ \\
Three minute after LMA insertion & $117.02 \pm 21.246$ & $99.62 \pm 25.071$ & $<0.001$ \\
\hline
\end{tabular}




\section{Conclusions}

The result of this study showed that LMA insertion condition summed score was comparable in ketofol group and propofol group. There was a decrease in propofol requirement for induction in the ketofol group. There was a more stable MAP picture in the ketofol group when compared to that of propofol group.

\section{Abbreviations}

ASA: American Society of Anesthesiologists; GABA: Gamma-aminobutyric acid; HR: Heart rate; KP: Ketofol; LMA: Laryngeal Mask Airway; MAP: Mean Arterial Pressure; NMDA: N-Methyl-D-Aspartate; P: Propofol

\section{Acknowledgments}

The authors acknowledge Addis Ababa University, the supervisors, data collectors, and study participants for their invaluable support.

\section{Funding}

No funding was received.

\section{Availability of data and materials}

The datasets generated and/or analyzed during the current study are available on the corresponding author and will be submitted upon request for securing confidentiality.

\section{Author's contributions}

BA: Conceive of data and designed the study, supervised the data collection, performed the analysis, interpretation of data, drafted the manuscript and final approval of the revision for publication. AA: Assisted in designing the study, data interpretation and critically reviewed the manuscript. HT: Assisted in designing the study, data analysis, data interpretation and reviewed the manuscript critically. GT: Assisted in analysis, methodology, and interpretation of the data with the statistics and reviewed the manuscript critically. Agreement to be accountable for all aspects of the work in ensuring that questions related to the accuracy or integrity of the work are appropriately investigated and resolved. All authors also read and approved the final manuscript.

\section{Ethics approval and consent to participate}

Ethical clearance and approval were obtained from the ethical review committee, Addis Ababa University College of health sciences. Permission to conduct was obtained from Menelik II hospital. The purpose of the study was explained to the family of patients under the study and written informed consent was obtained from the family of each patient. The patients' family was informed that the care to be given was not be compromised in any way and confidentiality was assured. Name and other identifying information were not used in the study.

\section{Consent for publication}

Not applicable.

\section{Competing interests}

The authors declare that they have no competing interests.

\section{Publisher's Note}

Springer Nature remains neutral with regard to jurisdictional claims in published maps and institutional affiliations.

\section{Author details}

1Aksum University, PO box 298, Aksum City, Tigray, Ethiopia. ${ }^{2}$ Addis Ababa University, PO box 811/1000, Addis Ababa, Ethiopia.

Received: 11 April 2018 Accepted: 10 March 2019 Published online: 20 March 2019

\section{References}

1. Mohamad RL, Tang S, Yahya N, Izaham A, Yusof AM, Manap NA. Comparison between effects of ketamine and midazolam as co-induction agents with propofol for prosealTM laryngeal mask insertion. Sri Lankan J Anaesthesiol. 2016;24(1).
2. Pavani Kalyanam HLBR, Praveen Kumar M, Rangarao D. Comparison of Propofol versus Propofol + ketamine for LMA insertion in children undergoing elective eye surgery. Int J Adv Health. 2015;2(5):592-601.

3. Benumof JL. Laryngeal mask airway and the ASA difficult airway algorithm. Int Anesthesiol Clin. 1998;36(2):61-90.

4. Brain A, McGhee T, McAteer E, Thomas A, Abu-Saad M, Bushman J. The laryngeal mask airway. Development and preliminary trials of a new type of airway. Anaesthesia. 1985;40(4):356-61.

5. Scanlon P, Carey M, Power M, Kirby F, Brown BR Jr. Patient response to laryngeal mask insertion after induction of Anaesthesia with Propofol or Thiopentone. Surv Anesthesiol. 1994;38(4):194.

6. Eftekhari J, Haki BK, Tizro P, Alizadeh V. A comparison to facilitate insertion of the laryngeal mask: term of recovery and postoperative nausea and vomiting after anesthesia with propofol-atracurium and thiopentalatracurium. Acta Medica Iranica. 2015:53(2):117-21.

7. Seyedhejazi M, Eydi M, Ghojazadeh M, Nejati A, Ghabili K, Golzari SE, et al. Propofol for laryngeal mask airway insertion in children: effect of two different doses. Saudi J Anaesth. 2013;7(3):266

8. Gupta A, Kaur S, Attri JP, Saini N. Comparative evaluation of ketaminepropofol, fentanyl-propofol and butorphanol-propofol on haemodynamics and laryngeal mask airway insertion conditions. J Anaesthesiol Clin Pharmacol. 2011;27(1):74

9. Hosseinzadeh H, Eidi M, Ghaffarlou M, Torabi E, Ghabili K, Golzari S. Comparison of remifentanil with esmolol to blunt the cardiovascular response to tracheal extubation in patients undergoing neurosurgical procedures for intracranial masses. J Pak Med Assoc. 2013;63(8): 950-4.

10. Hosseinzadeh H, Eidy M, Ghaffarlou M, Ghabili K, Golzari SE. Esmolol: a unique beta-blocker in maintaining cardiovascular stability following neurosurgical procedures. Adv Pharm Bull. 2012;2(2):249.

11. Furuya A, Matsukawa T, Ozaki M, Nishiyama T, Kume M, Kumazawa T. Intravenous ketamine attenuates arterial pressure changes during the induction of anaesthesia with propofol. Eur J Anaesthesiol. 2001;18(2): 88-92.

12. Yousef GT, Elsayed KM. A clinical comparison of ketofol (ketamine and propofol admixture) versus propofol as an induction agent on quality of laryngeal mask airway insertion and hemodynamic stability in children. Anesth Essays Res. 2013;7(2):194.

13. Gül R, Hizli Ş, Kocamer B, Koruk S, Şahin L, Kilinçaslan H, et al. The safety and efficacy of remifentanil compared to fentanyl in pediatric endoscopy. Turkish J Med Sci. 2013;43(4):611-6.

14. Smischney NJ, Beach ML, Dodds TM, Koff MD. Ketofol as a sole induction agent is associated with increased hemodynamic indices in low-risk patients. Anesthesiology. 2011;16:A485.

15. Ghatak T, Singh D, Kapoor R, Bogra J. Effects of addition of ketamine, fentanyl and saline with Propofol induction on hemodynamics and laryngeal mask airway insertion conditions in oral clonidine premedicated children. Saudi J Anaesth. 2012;6(2):140

16. Khutia SK, Mandal MC, Das S, Basu S. Intravenous infusion of ketaminepropofol can be an alternative to intravenous infusion of fentanylpropofol for deep sedation and analgesia in paediatric patients undergoing emergency short surgical procedures. Indian J Anaesth. 2012;56(2):145

17. Goh P, Chiu C, Wang C, Chan Y, Loo P. Randomized double-blind comparison of ketamine-propofol, fentanyl-propofol and propofol-saline on haemodynamics and laryngeal mask airway insertion conditions. Anaesth Intensive Care. 2005:33(2):223.

18. Hui T, Short T, Hong W, Suen T, Gin T, Plummer J. Additive interactions between Propofol and ketamine when used for anesthesia induction in female patients. Surv Anesthesiol. 1996:40(2):81.

19. Ozgul U, Begec Z, Karahan K, Erdogan MA, Aydogan MS, Colak C, et al. Comparison of propofol and ketamine-propofol mixture (Ketofol) on laryngeal tube-suction II conditions and hemodynamics: a randomized, prospective, double-blind trial. Curr Ther Res. 2013;75:39-43.

20. Singh R, Arora M, Vajifdar $H$. Randomized double-blind comparison of ketamine-propofol and fentanyl-propofol for the insertion of laryngeal mask airway in children. J Anaesthesiol Clin Pharmacol. 2011;27(1):91

21. Goel S, Bhardwaj N, Jain K. Efficacy of ketamine and midazolam as coinduction agents with propofol for laryngeal mask insertion in children. Pediatr Anesth. 2008;18(7):628-34. 
22. Begec Z, Demirbilek S, Onal D, Erdil F, Ilksen Toprak H, Ozcan Ersoy M. Ketamine or alfentanil administration prior to propofol anaesthesia: the effects on ProSeal ${ }^{T M}$ laryngeal mask airway insertion conditions and haemodynamic changes in children. Anaesthesia. 2009:64(3):282-6.

23. Ghafoor HB, Afshan G, Kamal R. General anesthesia with laryngeal mask airway: etomidate vs propofol for hemodynamic stability. Open J Anesthesiol. 2012;2(4):161-5.

Ready to submit your research? Choose BMC and benefit from:

- fast, convenient online submission

- thorough peer review by experienced researchers in your field

- rapid publication on acceptance

- support for research data, including large and complex data types

- gold Open Access which fosters wider collaboration and increased citations

- maximum visibility for your research: over $100 \mathrm{M}$ website views per year

At BMC, research is always in progress.

Learn more biomedcentral.com/submissions 